\title{
NOTES ON THE BURROW ECOLOGY AND FOOD HABITS OF THE BURROWING OWL IN SOUTHWESTERN NORTH DAKOTA
}

\author{
by Ted R. James and Robert W. Seabloom, Department of Biology, \\ University of North Dakota, Grand Forks, North Dakota
}

A sizeable population of the Burrowing $\mathrm{Cwl}$ (Speotyto cunicularia) occurs on the prairies of southwestern North Dakota. During the summer of 1964, the burrow ecology and food habits of this owl were studied on these semi-arid mixed grass prairies. Observations were made at 15 burrow sites in Bowman, Billings, and Slope counties, and owl pellets were collected from eight active burrow systems in Slope County during July and August. The mammalian, avian, and insect remains found in these pellets were identified using standard techniques and comparative specimens.

Burrowing Owls were observed to use abandoned badger and prairie dog holes. These burrows were on flat terrain or well drained gentle slopes, and were associated with grazed pastures. There was no evidence that the owls had excavated their own burrows, or had enlarged or modified the excavations of other animals.

The numbers of individual holes used by owl families varied from two to 10. In addition to a main burrow or nest hole, most burrow sites were found to have one to three satellite or surrounding holes. The nest hole was always the largest and received the greatest use. Satellite holes varied from small unvegetated depressions in the surface, to larger excavations nearly the size of the nest hole, and were 25 to 75 yards from the main burrow. Debris and rejected pellets were sparse in the vicinity of these satellite holes, which were apparently used by adult owls as resting and observations posts. When owl families were approached on foot, any juveniles would retreat within the nest burrow, while the adults would invariably fly to one of these other nearby holes.
All main burrows contained debris. Those holes receiving the greatest use contained a thick accumulation of excrement, feathers, fresh and disintegrated pellets, and bits of cow dung. Evidence indicated that once owls took possession, they made no attempt to clean a burrow system. They apparently regurgitate pellets anywhere in and about the burrow area, since pellets were found not only around the burrow, but also well inside the entrance.

Roberts (1932) reported that jack rabbits are the first to occupy abandoned badger dens, with Burrowing Owls using these holes after the jack rabbits have relocated. He further indicated that when owls take possession, they proceed to clean the burrow system, and heap up the rabbit leavings before the burrow opening. Our observations do not support this suggested tenant succession. Owls apparently did little burrow improvement or sanitation; jack rabbits, however, were infrequent users of these burrows. Jack rabbits also of ten used elevated badger mounds as observation points and dusting areas, which may explain the presence of rabbit pellets in the vicinity of these mounds.

Burrowing Owls have been reported to have a wide spectrum of foods, including larval and adult insects, small mammals, various birds, and fish, in central Iowa, Minnesota, and the eastern Dakotas (Baird, et al., 1874; Roberts, 1932; Scott, 1940; Schmid, 1959; Grant, 1965). Our study supplements those of previous workers, and provides information on the food habits of this species in another area.

The analysis of the contents of 42 Burrowing Owl pellets is presented in Table 1. No attempt was made to 
TABLE 1. Prey of the Burrowing Owl, based on analysis of 42 pellets from Slope County, North Dakota.

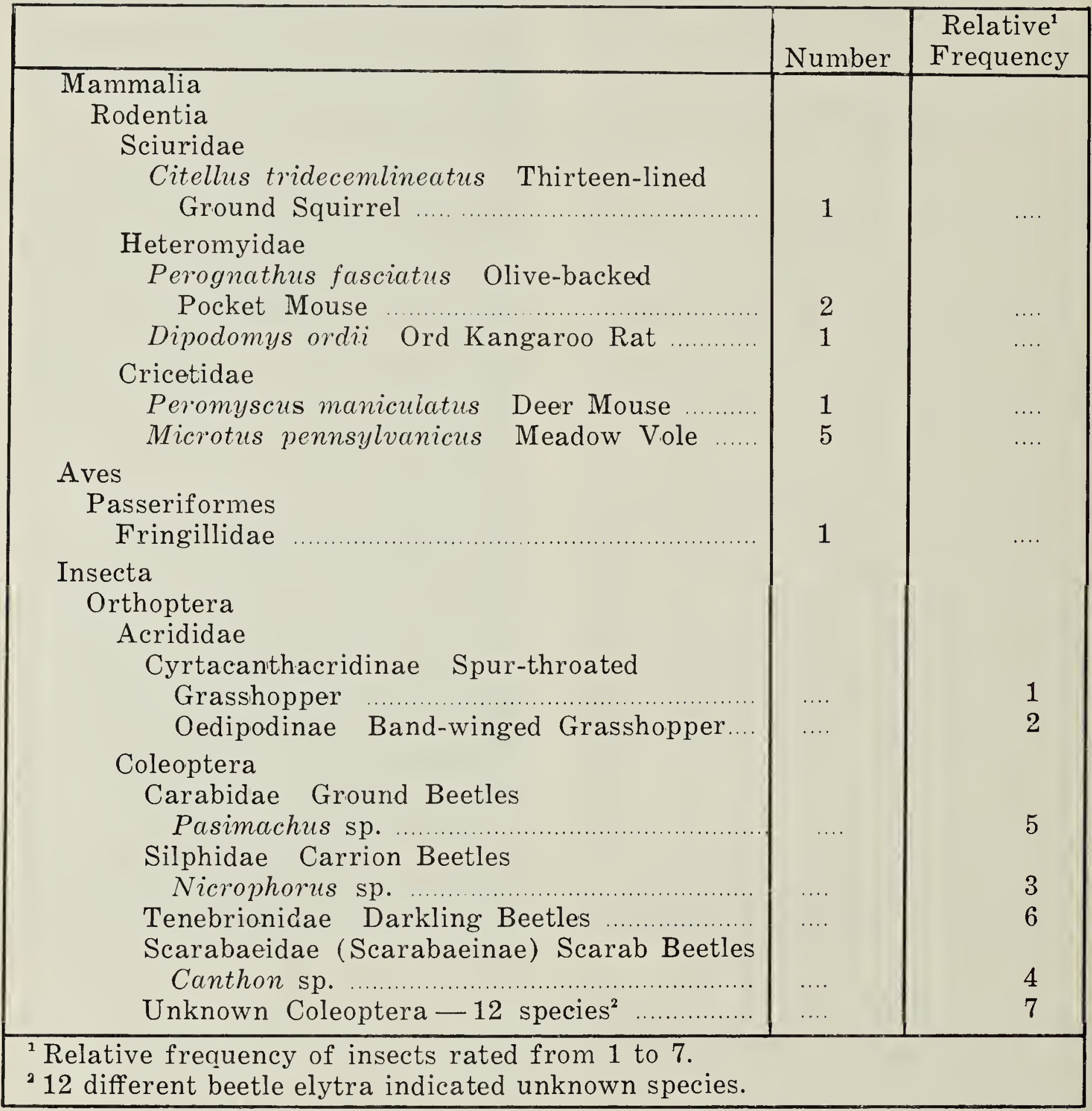

determine the number of each species of insect; however, the relative amounts of insect material were recorded. While predation on vertebrates was recorded, the mid to late summer diet of the Burrowing Owl consisted predominantly of insects, with grasshoppers comprising the greater share of the prey. Frequently pellets consisted almost exclusively of grasshopper remains. Carrion beetles, ground beetles, and other moderate to large size coleopterans made up the remainder of the insect diet. Pellets containing insects also contained considerable amounts of grasses, other plant material, and grains of sand. The incidence of these substances in pellets may indicate that this owl preys primarily on resting insects rather than on insects in flight.

\section{LITERATURE CITED}

Baird, S. F., T. M. Brewer, and R. Ridgway. 1874. A history of North American birds. Little, Brown \& Co., New York. 3 vol.

Grant, R. A. 1965. The Burrowing Owl in Minnesota. Loon, 37:2-17.

Roberts, T. S. 1932. The birds of Minnesota. Univ. Minn. Press, Minneapolis. 2 vol.

Schmid, W. 1959. Note on the food habits of the Burrowing Owl in Minnesota. Flicker, $31: 103$.

Scott, T. G. 1940. The westerr burrowing owl in Clay County, Iowa in 1938. Am. Midl. Nat., 24 :585-593. 